\title{
Study on Strategic Planning of Road and Bridge Infrastructure Development in City Planning: Taking Porto-novo City of Benin Republic as Example
}

\author{
Dossa Didier Boko-haya ${ }^{1,2}$, Yadong Li ${ }^{1}$, Koffi Togbenou ${ }^{1,2}$, Saizhi Liu ${ }^{1}$, Changrong Yao ${ }^{1}$ and Bin Qiang ${ }^{1}$ \\ ${ }^{1}$ School of Civil Engineering, Southwest Jiaotong University, Chengdu 610031, China \\ ${ }^{2}$ Polytechnic School of Abomey-Calavi (EPAC), University of Abomey-Calavi (UAC), 01 POB: 526 Cotonou, Republic of Benin
}

\begin{abstract}
Concern about the townlet infrastructure construction in developing country is one of the crucial part of county town planning and development. By taking the overall planning and design in a case study of Porto-novo city at Republic of Benin, this paper analyzes the characteristics and opportunities of Porto-novo city and puts forward corresponding infrastructure construction strategy. In the end, the paper comes up with specific plan of planning and design under the background of Porto-novo's planning of development strategy.
\end{abstract}

\section{Introduction}

Geographically located in the east of the Benin and also situated at the southeast of Cotonou city, Porto-novo city is known as "the political capital of Benin" and is the traffic hub and material distribution center of road transport in southern of Benin and Nigeria. As such, Porto-novo needs to develop well balanced integrated multimodal transit systems, bridges and road networks by best utilizing the natural strength of each individual mode for the efficient movement of passengers and goods as well as integrate itself with the local, national and regional countries particularly with Nigeria to expand international trades through transportation networks.

Now, with Porto-novo city becoming increasingly established as Benin's political capital, large steps are being taken to alleviate these pressures through a range of improvement projects within the city and its surrounds. In this regard, the West African Urban Planning and Design (WAUPD) and National Development and Reform Committee (NDRC) of Benin preliminarily discussed the regional planning, design and development of CotonouPorto-novo Economic and Politic Zone [1-2]. Situated at the banded development axis of Cotonou-Porto-novo Economic and Politic Zone and according to a series of strategic thinking, the national government of Benin (NGB) has recently passed Urban Development Strategic Planning (UDSP) of Benin (hereinafter referred to as Strategic Planning (SP)). The SP made new spatial arrangement of Porto-novo city's new urban planning, design and development. As one of the three significant cities with special status of Benin Republic [3], Portonovo city is included in the scope of new city. Thus, new thinking emerges in city infrastructure planning, design and construction.
This paper is structured in the following way. In the subsequent section, we highlight the characteristic of Porto-novo city. In section 3, we present Porto-novo city under the background of strategies planning and development. Integrated Strategies and Design of Portonovo city's development priority needs are assessed in section 4. Section 5 finally concludes the paper and provides interpretations of where Porto-novo stands in this transition process, and how the city might be better positioned to achieve greater urban sustainability.

\section{Overview and characteristics of Porto- novo city}

The current study concerns the Porto-novo city which is one of the largest cities in West Africa (Figure1). Portonovo city, 34.1 kilometers away from Cotonou, is located at the east of Cotonou and has advantageous geographical location. It spreads over a total land area of $410 \mathrm{~km}^{2}$ and holds an estimated population of about one million.

\subsection{Convenient roads network and traffic}

A modern road network helps traffic move around the country more easily and is essential for any country economic growth. In this regard, Porto-novo city has convenient traffic, Porto-novo-Akpro Misserete-Igolo road cross the center of Porto-Novo, which connects Porto-novo with Cotonou and Nigeria. The national highwayRNI1 [4],Hillacondji-Cotonou-Porto-novo-Akpro Misserete-Igolo expressway and Cotonou-Porto-novo railroad cross the south-east part of the country. So far, Porto-novo has basically achieved the goal that linking each village with highways. It's well developed in the east 
and has formed network-based highway pattern as depicted in Figure 1.

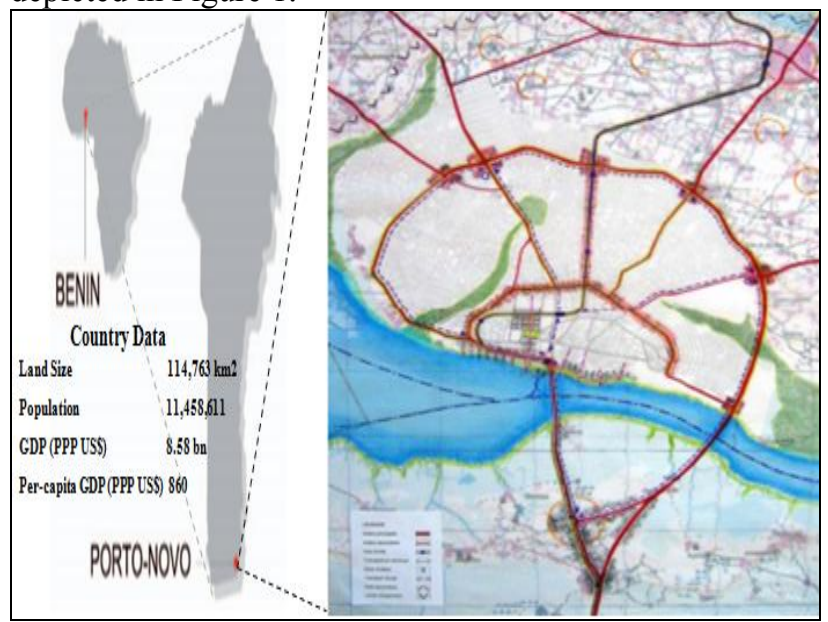

Figure 1. Country data and map of Porto-novo and it relationship to the city, Republic of Benin.

\subsection{Weak economic foundation and industrial structure}

Though Porto-novo has superior location advantage, its economic foundation is weak. Agricultural structure lacks of adjustment, the development of secondary industry is restricted and the tertiary industry just starts. All these obstructs Benin economic development [5-9].

\subsection{Abundant tourism resource}

Porto-novo city is probably the richest and most diverse heritage of any city in Benin Republic. Within 600 acres in the center of the city, history has left its footprint in the presence of successive Goun and Yoruba people, settlers and slaves, in comers from Brazil, these main four influences mingle and stand in the city creating the Portonovo we know today. It's this past which has given the city such a diversity of place, people, culture and customs that can be found today.

In recent years, Porto-novo has undergone rapid growth, and this coupled with often severe climatic conditions has resulted in strains and pressures on its infrastructure, environment and the functioning of the city as a whole.

\section{Porto-novo city's opportunities under the background of strategic planning}

\subsection{Opportunities brought by convenient bridge and road infrastructure development}

Communities with good public transit systems are economically thriving communities and offer location advantages to businesses and individuals choosing to work or live in them [10-11]. Porto-novo has complete traffic network, which lays solid foundation for its development. National highway RNI1 crosses Porto-novo city from the south part of the country, Hillacondji-Porto- novo highway and Cotonou-Porto-novo railroad cross it administrative region. Further, the district's development will generate an increasing traffic flow. Thus, considering that the building of the "second bridge" answers to a real need of the city. In this regard, the bridge to be build will be placed at the west side of Lokpodji (an important new door for Porto-novo) at the limit between the entrance of the district and the rest of the city. The two valleys which traverse Lokpodji, on the East and West, will be recovered to facilitate the drainage of rainwater into the lagoon, without completely planning them. This approach allows the preservation of this exceptional and rich natural ecosystem. The bridges will be the connexion between the different ways of communication. Thus, developed traffic (bridge and road infrastructure) provides convenient channel for Porto-novo city's goods and population flowing to other areas; meanwhile, it can promote the development of Porto-novo city's tertiary industry such as trade and tourism (Figure 2).

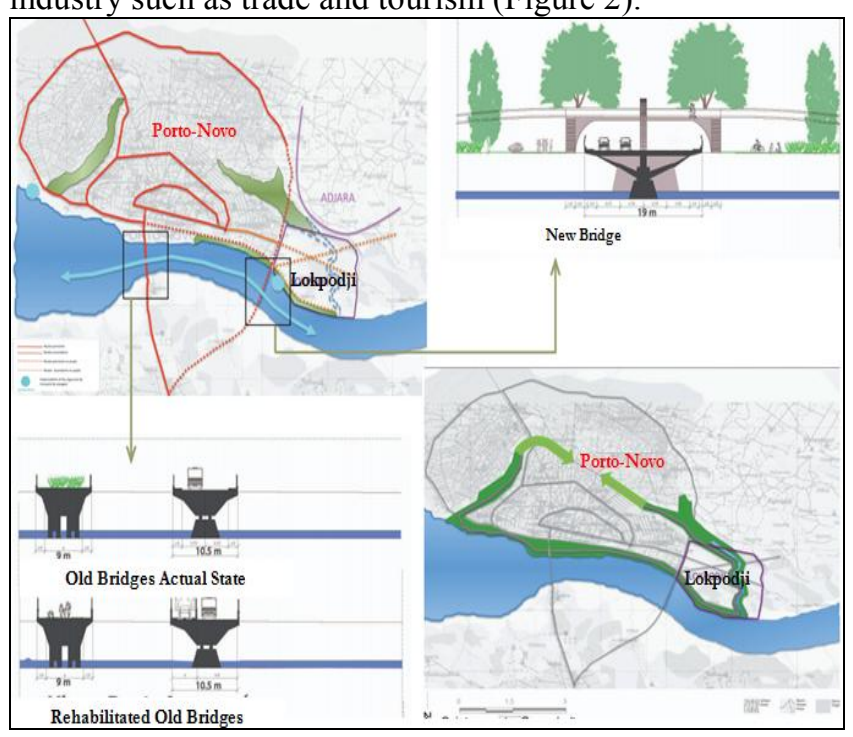

Figure 2. New bridges changing the city conception and the green belt

\subsection{Opportunities brought by land use changes of city and county}

The SP made a new scope demarcation of the new city (Figure 3). Then center of Porto-novo city and its villages such as Ganvie village and Lokpodji village are included in the urban development land, which have become several housing cluster in the development strategy of Benin Republic county.

In Porto-novo's space layout, Porto-novo takes its main city area as the core and forms the layout of "one center has three parts embraced by periphery lake". The current public administration building is no longer relevant in the city center, they could be located on other or less strategic areas. Though the property change of land use brings Porto-novo city with unprecedented challenges, it is a scarce opportunity for the city as whole. 


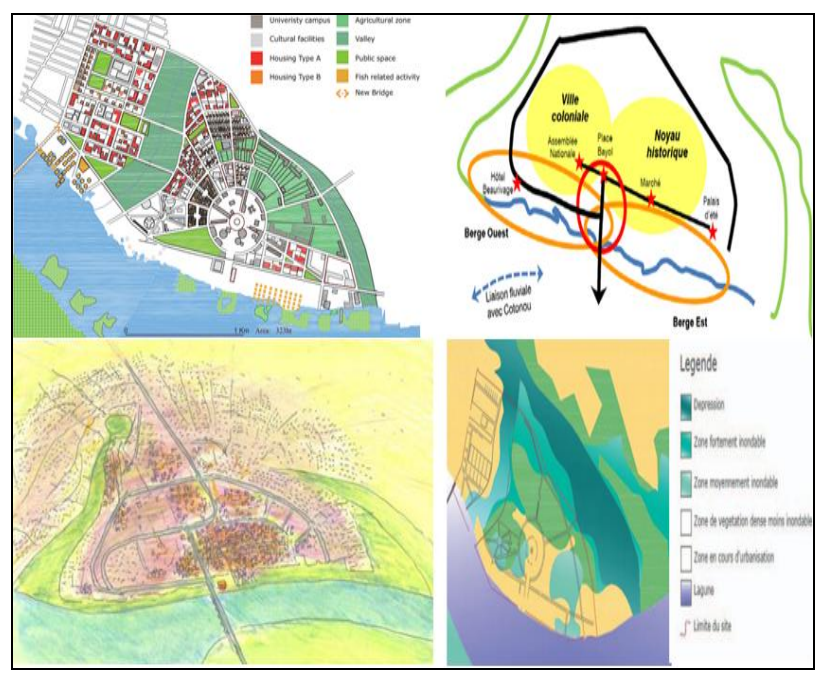

Figure 3. Strategic planning of Porto-novo city

\section{Integrated strategies and design of Porto-novo city's development needs}

\subsection{Development strategies of Porto-novo city}

\subsubsection{Playing location advantage and strengthen radiation function}

In the future development, Porto-novo city, situated at the central part of Cotonou and Nigeria county, should position from the overall development of Porto-novo's new towns and strengthen its connection with Cotonou, Calavi-Kpota (rossing Nokoue lake) and Nigeria to make harmonious development with Benin and Nigeria Republic and achieve mutual benefit of economic society.

As a development of new city, Porto-novo should accelerate its construction of various infrastructures and public service facility, strengthen its connection with other towns and cities. For instance, Calavi-Kpota can conveniently be connected with many destinations of Porto-novo through roadways via the lake Nokoue. Major road and bridge development activities should also focus on improving intermodal connectivity (e.g., physical integration of all feasible modes at strategic transportation hubs) and highway safety as well as maintaining roadways for quality service. Furthermore, technology should be used to improve safety and operational efficiency of all modes.

\subsubsection{Optimizing the industrial structure to enhance economic strength}

Industrial structure has a close relationship with economic development. As the industrial structure in Porto-novo city is relatively unitary, there is a need to concentrate on upgrading the industrial structure, changing the single structure, therefore adapting it to modern economy growth and laying a solid foundation for the long-term development of the town. In this regard, we also should spare no efforts to promote the development of the secondary or third industry, thus forming a coordinate development of economy layout. For instance, stimulate the region's economic prosperity by developing the characteristic agriculture along main line and achieve urban development strategy by improving the service level of tourism industry.

\subsubsection{Highlighting historical culture and protecting the ecological environment}

Porto-novo city, named for "Hogbonou Eucharistus " due to its profound culture background, was constructed in 1752. Protecting history cultural heritage is the premise of ancient city's development and improvement, so to preserve this resource, the state took the initiative with a Special Program of Rehabilitation (SPR) of the city of Porto-novo (PSRPN) in the late 1990s. Many of the richest and most diverse heritage also remained intact as well as the ancient streets and famous residential houses with Beninese traditional cultural feature. Toffa $1^{\mathrm{er}}$, a Beninese revolution pioneer, whose native place adds more historical and herotical glory in this area. Inside the Porto-novo city has the picturesque scenery and historic celebrities.

As the indispensible scenery tourism area in Benin, Porto-novo possesses not only the unique human landscape and history background, but also uncommon ecological environment. Dynamic coordination should be used to improve transportation road network and environment. In this regard, the sustainable transportation characteristics [12] including: (i) traffic development combines with ecological environment protection and land use and (ii) traffic system not only meets the present social economic development's needs, but also provides development space for future sustainable development, would be needed.

\subsection{Practical considerations of planning and design for Porto-novo city}

Through the analysis of Porto-novo city's resources, socio-economic, environment conditions and super ordinate planning, Porto-novo positions itself as a living area for Benin county's development, ecotope, a backyard garden, and tourism service center of the county.

\subsubsection{Porto-novo city system planning}

Porto-novo city divides each village's level and scale in accordance with three levels 'City domain center, basiclevel village and key village', then the function system which is multi-level, multifunction and farm-out is formed. The area is framed by the Donoukin valley and serviced by a new road and bridge, connecting it to the wider city as whole (Figure 4).

Urban growth identified in this area would occur gradually, over a long period of time would be less dense in character. In this regard, the aim would be to prioritize public services assets including: (i) Supporting local business: growing wood and raphia (for construction), exploiting potential uses for water hyacinth, agriculture and market gardening; (ii) Schools and training colleges 
(with a focus on agriculture, fishing and environmental or ecology studies); (iii) Health facilities and (iv) Sports and leisure facilities.

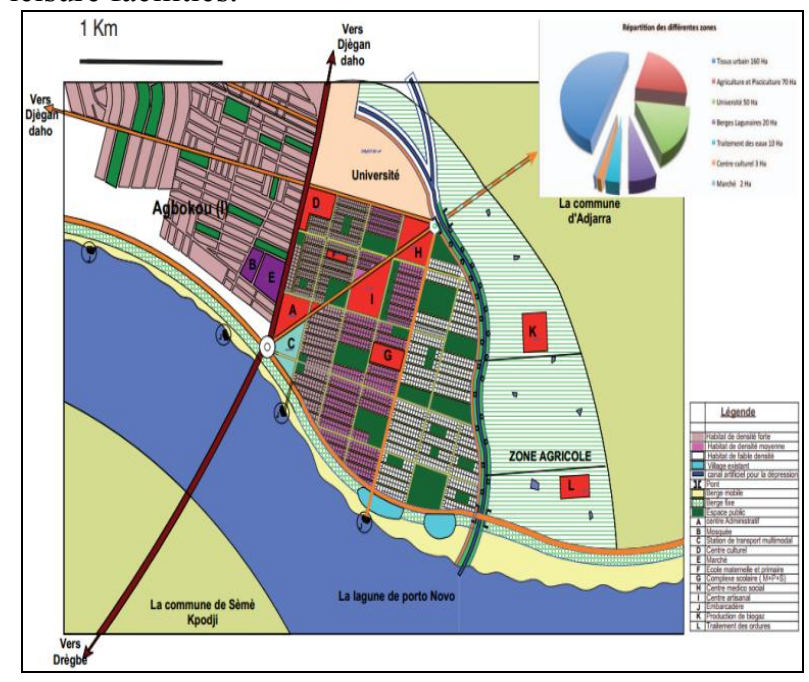

Figure 4. Porto-novo city system planning

\subsubsection{The overall plan of the township}

According to the new city development orientation, the distribution of construction land and long-term development trend, the new township relies on the arterial traffic and take a town built up area as the center, focusing on the development of the east, properly on the north and south development, then form a layout structure which is one center and five districts (Figure 5).

This plan naturally optimizes the space layout, keeps the integrity of the historical and cultural blocks in the old area. At the same time, Porto-novo city should develop properly and construct express way to make it more convenient to reach Benin Republic country, thus it can form a new economic growth polar.

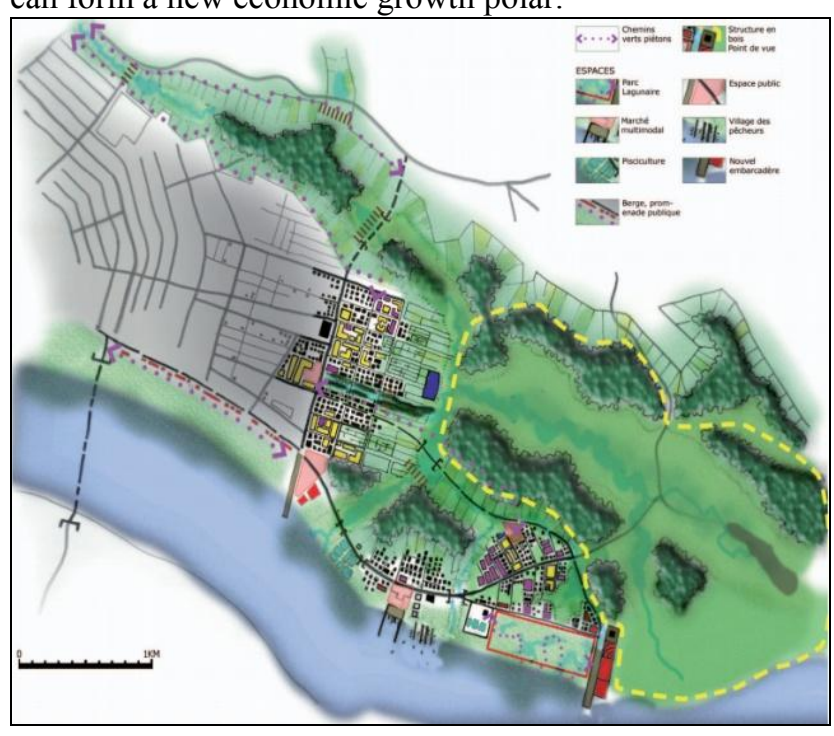

Figure 5. Overall plan of the township

\subsubsection{Protection of famous historical and cultural city}

The protection, inheritance and development of the city pattern plays an important role in protection of a famous city [13]. The historical blocks of Porto-novo city are concentrated, their style and features are based on eastern Cotonou's row dwellings, mixing multifarious celebrity culture. In the protection planning, the protection of ancient town's overall style and features include street space record, architectural pattern and key cultural relics. Simultaneously, the city highlights local characteristic history and culture.

By maintenance and arrangement Porto-novo exploits and utilizes its tourism resources reasonably. Taking the Lokpodji street as the center, the "ancient bridge" as the link, Porto-novo city divides its old town into two parts (south and north). Then an ancient city tourism center including Ganvie park is formed. To meet the tourism and life needs of town center Porto-novo offers necessary tourism, living, service and educational facilities.

\subsection{Planning innovation key points}

In order to highlight the characteristics of Porto-novo city, to create atmosphere of tourism landscape town and keep with the development of Republic of Benin's new city, this planning makes some considerable attempts.

Firstly, Porto-novo will lucubrate its historical blocks' protection, planning, design and highlight the fundamental keynote of ancient city to form tourism node. Simultaneously, Porto-novo should protrude the use of visual landscape and natural elements in the overall planning stage.

Secondly is that in the classification of land use planning, urban land classification criteria is used, that means Porto-novo city is not regarded as township land, but regarded as the city land to be planned. Thus, Portonovo city not only meets the need of its city function, but also realise its urban group function after the development of the new city.

\section{Conclusion}

Porto-novo has been experiencing a very high rate of population growth and urban expansion. According to its characteristics and development of resources, location, industry and economic structure, construction and development of county townlet should adopt its good points and avoid its shortcomings to form its own unique advantages.

From the perspective of regional coordination, the overall planning of Porto-novo makes a preliminary design of urban development strategy, development tendency and urban and rural bridge and road traffic system. In order to optimize urban space, to promote the economic competitiveness and to realise common prosperity in urban and rural areas, under the circumstances that the use of city's urban and rural land changed, this planning takes the development condition and development factors as the key analyzing point.

\section{Acknowledgment}

The authors would like to thank the funding bodies of this study: the University of Southwest Jiaotong (Department 
of Bridge Engineering) under the Project Numbers (No. (VP13KJ1101Y14001 and 51378430).

The first and third authors would like to acknowledge and thank the Professors Cossi N. Awanou, Basile B. Kounouhéwa, Aristide B. Akpo and Clement A. Kouchade; and Dr Gabin Koto N'Gobi and Dr Ossénatou Mamadou for their continued support and encouragement.

Other important contributions of the research were made by Prof. Zhang Xun.

The conclusions in this paper are those of the authors of this paper or based on the referenced literature.

\section{References}

1. A. Anais, M. Schut. Discussion on Strategy and urban design for the city center of Porto-novo. pp.44-57, (2013).

2. El. Samia, B. Cukierman, A. Pringle. Discussion on Analysis of Urban Planning \& Development PortoNovo, Benin. Second Edition, pp.22-36, (2013).

3. Republic of Benin.Law ${ }^{\circ} 98-005$ on the organization of municipalities with special status of Benin (2001), (Accessed 18.08.2017).

4. Republic of Benin, Decree No.2001-092 of Feb. 20, 2001. Classifying economic, tourist or strategic routes of interest, pp.3-6, (2001).

5. D.D. Boko-haya, Y.D. Li, X.X. Liao, C.R. Yao, C.J. Wang and Q.Q. Xiang. Key issues and challenges in developing integrated road networks infrastructure with regional connectivity: A study case of Portonovo in Benin Republic. MATEC Web Conf., (to be published)

6. D.D. Boko-haya, Y.D. Li, C.R. Yao and B. Qiang. Investigation on bridges connection to network carrefour in existing roads in Africa big cities: the case of cotonou in Benin Republic. Int. J. Eng. Res. App. 6(4), pp. 53-61, (April-2016).

7. C.Dominguez-Torres, V.Foster.Benin's infrastructure:a continental perspective.Africa infrastructure country diagnostic country report. World Bank, Washington, DC, (2011).

8. D.D. Boko-haya, Y.D. Li, C.R. Yao, S.Z. Liu and Q.Q. Xiang. Road and Bridge Infrastructure Development Issues in Benin Republic: Analysis and Perspectives. American Journal of Civil Engineering. 5 (1), pp. 9-15, (2017).

9. D.D. Boko-haya.; Y.D. Li, S.Z. Liu, C.R. Yao, Q.Q. Xiang and B. Qiang. Assessment research on capacity strengthening in bridge and road development in the Republic of Benin. (to be published)

10. E. Zavadskas; R. Liias, Z. Turskis. Multi-attribute decision making methods for assessment of quality in bridges and road construction: State of the art surveys. Balt. J. Road Bridge Eng. 3, pp.152-160, (2008).

11. D.D. Boko-haya, Y.D. Li, C.R. Yao, Y. Gu, B. Qiang, and Q.Q. Xiang. Development of conceptual model for overcoming the challenges of road and bridge infrastructure development: towards innovative solutions in Benin Republic, Int. J. Eng. Res. Afr. 26, pp. 161-175, (2016). DOI: 10.4028/www.scientific.net/JERA.26.161

12. J. Yin, F. Li, X. H. Li. Research on the sustainable transportation development strategies in the developed countries. Traffic \& Transportation, 7, pp.39-42, (2009).

13. Z. J. Dong, G. Zhang, H. M. Liu. Protection and development of famous historical and cultural cities based on sustainable development-a case study of Nanjing, Study Theory, 22, pp. 3-4, (2000). 